\title{
Assessment of the Impact of Cloud Technologies on Social Life in the Era of Digitalization
}

\author{
https://doi.org/10.3991/ijim.v15i21.22985
}

\author{
Elena Panfilova ${ }^{1(\bowtie)}$, Anna Lukyanova $^{2}$, Nikolay Pronkin $^{3}$, Elena Zatsarinnaya ${ }^{4}$ \\ ${ }^{1}$ State University of Management, Moscow, Russian Federation \\ ${ }^{2}$ Financial University under the Government of the Russian Federation, \\ Moscow, Russian Federation \\ ${ }^{3}$ Sechenov First Moscow State Medical University (Sechenov University), \\ Moscow, Russian Federation \\ ${ }^{4}$ Plekhanov Russian University of Economics, Moscow, Russian Federation \\ panfilovaelena@yahoo.com
}

\begin{abstract}
Due to the expansion of new digital trends in the strategic development of territorial units, it became necessary to structure the socio-economic effects from the introduction of innovative technologies grounded on cloud computing. The novelty of the study is explained by the popularity and active development of modern technologies in all spheres of social life in the era of digitalization that require the necessity to study the peculiarities of their influence on the modern life of society. Realized the identification of cloud technologies impact on the social life in the era of digitalization, an online conference was held between representatives of government, business, science, and education of the Republics of Karelia, Komi, Adygea, Dagestan, Ingushetia, Kalmykia, Karachay-Cherkessia, Krasnodar Krai and Stavropol Krai (Russian Federation). In the context of innovative possibilities of platform economy, in discussion were identified the key effects of the cloud solutions implementation in the Russian Federation regions development prospect strategy. The results of the experiment based on the study of the influence of the implementation of cloud solutions on the regional development level show such effects as social and human capital foundation, improvement the quality and standard of living in a region and social interaction, development of social constructivism, economic potential and competitiveness of social capital. The analysis of the received results indicates the positive social effects of cloud technologies at the level of a territorial unit are achieved by increasing digital literacy of the population and opening up new opportunities and platforms for social interaction and constructivism; providing the population with convenient services and open data for participation in active social, economic and political life. Based on the experiment it's determined that cloud technologies help to form a digital educational environment, modernize educational programs for the preparation of high-quality labor resources, develop digital infrastructure of individual settlements, create user content to preserve socio-cultural identity, and popularize a region in the global information space. The results of the experiment also show the opportunity to increase the population quality of living and ensure the growth of the efficiency and productivity indicators of labor resources with the help of cloud technologies. The listed above are achieved by expanding the marketing capabilities of business structures, providing them with new business models and digital services; optimization of resource
\end{abstract}


management, digitization of business processes, and platform organization of labor. The prospects for the further research can be based on the study of the capabilities of cloud technologies in the formation of flexible and effective interregional and international cooperation in a region, having a positive impact on regional economy and social capital development.

Keywords-cloud computing technologies, digital trends, digitalization, regional development, socio-economic effects

\section{Introduction}

The digital transformation of the socio-economic life of society implies the following:

- fundamental structural changes;

- institutional reforms;

- changes in mind maps, norms and patterns of human behavior;

- widespread awareness raising and mobilization;

- adoption of an integrated approach to issues of sustainability;

- unprecedented problem solving.

Technological change plays a key role in long-term social transformation. With the emergence of "knowledge societies", many modern technological solutions are aimed at supporting the well-being of society [1,2].

Modern society is at the epicenter of digitalization. A wide range of interactions in almost all spheres of social life became the subject to digital change. Social media and online platforms have transformed the way people get information and entertainment, communicate, shop, learn, and work. Innovative digital business models based on extensive data about users and processes are being developed and introduced into the social and economic life of society. Applications and "smart" machines are functionally aimed at analyzing these data, automatically interpreting patterns and efficiently managing production processes in the context of Industry 4.0 [3].

The availability of cloud backup, affordable and relatively cheap data storage has led to the movement of user data to the cloud in the form of photos, audio and video materials, as well as metadata-information about the network and user activity [4]. Cloud computing innovation brings people, devices and associated computing closer together by leveraging the functionality of mobile sensors on consumer devices and sensors embedded in infrastructure [5].

Interaction with algorithmic systems expands and popularizes the world practice of managing social spaces. Datafication, increased computing power, more sophisticated algorithms, economic and political interest in efficient technology solutions, and the general trend towards digitalization have all contributed to the deployment of technological tools to streamline society [6]. An example of the transformation of the socio-economic paradigm of society's interaction is the development of a platform economy. The rapid development was influenced by the emergence of innovative 
information and communication technologies with embedded cloud computing algorithms. For example, companies such as Google, Facebook, Ebay have created digital platforms that provide a wide range of functionality, have led to the restructuring of technology markets, transformation of social communications and reorganization of business relationships on a global scale [7].

Digital technologies are changing the possibilities and boundaries of human perception and action, creating new forms of interaction that are no longer determined by physical presence: personal information or images become potentially available to a global audience, user data are "easily and cheaply stored" and remain in digital records. Modern digital realities are shaping a new social order based on continuous tracking and offering unprecedented new opportunities for behavioral influence on society [8]. For example, user interaction on social networks is driven by the work with content in the process of information consumption, sharing and creation, providing and stimulating interactions in the concepts of "one-to-many" and "many-to-many", thereby contributing to the self-reinforcing dynamics of social networks. A key aspect of this interaction is the ability to quick transfer information locally and globally among users, groups or communities through collaboration, information exchange and social learning. At the same time, the growing relevance of user-generated content forms a valuable source of knowledge for providing innovative models of socio-economic interaction, achieving positive effects in the development of social constructivism [9].

The globally ongoing digitalization processes demonstrate a close relationship between innovative technological solutions and the socio-economic aspects of society. Technological change is an autonomous process that largely determines social change [10].

In the digital software marketplace, cloud services are seen as a driver of economic growth thanks to the ability to leverage powerful computing resources on demand. The key benefits of using cloud computing are cost savings, increased productivity and efficiency, mobility and speed [9]. In addition to economic effects, the cloud computing technologies using has a significant impact on the transformation of social interactions, delineating a new trajectory for the social development. Therefore, the purpose of the article is to determine the impact of cloud technologies on social life in the era of digitalization. The following tasks were set:

- reveal the concept of cloud computing and describe its functional features;

- provide a description of cloud computing services;

- conduct an online discussion on the impact of cloud computing technologies on the development of modern regions between representatives of government, business, science, and education of the Republics of Karelia, Komi, Adygea, Dagestan, Ingushetia, Kalmykia, Karachay-Cherkessia, Krasnodar Krai and Stavropol Krai (Russian Federation);

- determine the key effects of the cloud solutions implementation in the Russian Federation regions development prospect strategy.

- identify the functional effects of cloud technologies on the social life of society in the era of digitalization. 


\section{$2 \quad$ Materials and methods}

\subsection{Theoretical and methodological background}

Cloud computing is a hugely successful service-oriented computing paradigm that has revolutionized the way people abstract and use computing infrastructure. Among the features that allow cloud computing to position itself as a universal paradigm for deploying new applications, is elasticity, low initial investment, fast time to market, and risk transfer $[11,12]$. Cloud computing includes many technical concepts that are changing computing infrastructure. Cloud computing technology based on two concepts: multitenancy and service orientation which implemented in the form of virtualization systems and web services. Cloud computing requires sufficient network capacity for data access, reliable and resilient service offerings, and a well-functioning technical infrastructure [9].

Cloud computing is a flexible and cost-effective service that meets the corporate needs of IT customers by providing such services as: software as a service (SaaS), platform as a service (PaaS), and infrastructure as a service (IaaS) (Figure 1). However, the service space is becoming more and more diversified. For example, Acceleration-as-a-Service (AaaS) has been proposed to accelerate applications provided by GPUs (graphics processing units) [13]. One of the cloud computing services that is gaining popularity in recent years is container as a service (CaaS) [14]. Examples of CaaS include Google Kubernetes, Docker Swarm, and Rackspace Carina, which offer the deployment and management of containers needed to run workloads in dedicated clouds and microcalls to enable fog computing [4]. Various cloud deployment methods have emerged to meet the needs of users, social groups, communities and institutions. Last time, virtualization has become a milestone in ensuring optimal use of information technology resources. Cloud computing has transformed the economics of IT businesses and organizations from capital spending to operating expenses [15].

Cloud computing is transforming the way information technology services are developed, deployed, maintained, scaled, upgraded, and paid. Cloud computing is not so much a technology as a combination of many existing technologies [16]. The cloud is a distribution computing system, which is formed by interconnected virtualized computers, dynamically represented as one or more unified computing resources on the basis of a formal agreement between the customer of the service and its provider (SLA) [17]. The advantage of using the cloud is the full use of information technology resources. The cost of maintaining and managing these resources is enormous and can be saved by centrally managing the private cloud infrastructure [15].

Efficient use of the power of IT infrastructure through scalable software and hardware resources, rapid deployment, parallel batch processing, business intelligence and interactivity of mobile applications allows cloud services to maintain a prompt response to user requirements [18]. 


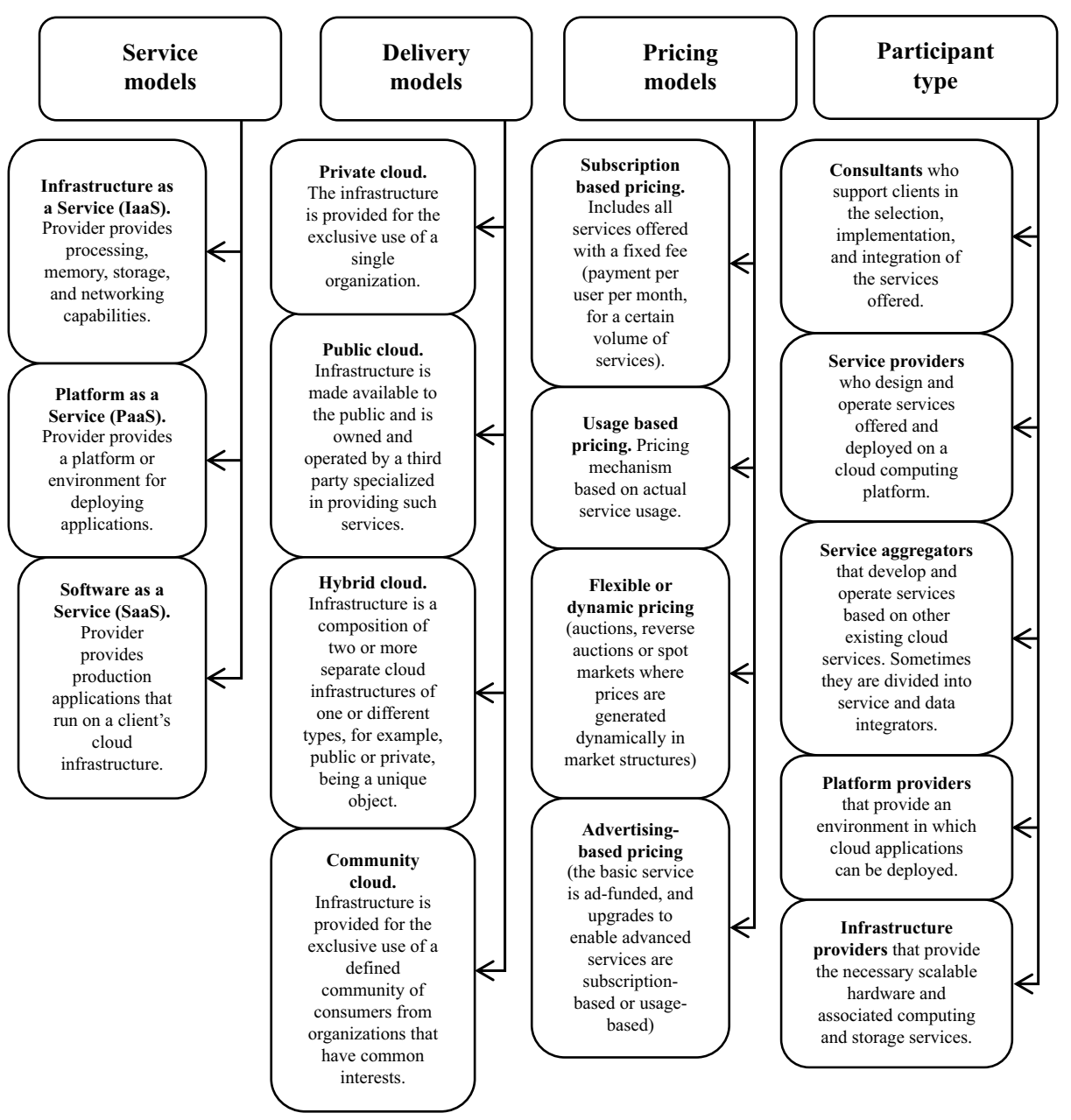

Fig. 1. Characterization of cloud computing services. Developed by the authors based on [9]

The cloud paradigm implements the processing, storage and control of data in one place on the server, thereby increasing the cost and subjecting the project to long delays and high network traffic. The benefits provided by fog computing are an extension of the cloud computing paradigm. Fog computing makes the cloud more like a network architecture, extending cloud computing to the edges of the network. Fog computing technologies place peripherals at the edge of the IoT network with low latency and high performance. Thus, the data are processed locally and sent to a central server. Using fog computing, application components run in cloud and fog [19]. 


\subsection{Study design}

In the context of technological opportunities, conceptualization of the relationship between technology, society and digitalization occurs in the ways of social constructivism and co-production [3]. (1) The approaches of social constructivism conceptualize technology as a product of society, indicate that technologies do not develop outside social processes in a linear way, but are the result of social activities and social communication. The technology is developed taking into account the cultural, economic, political, or organizational context. The social construction of technology emphasizes the multidirectional nature of technological development. From this point of view, digitalization is a process in which society, and therefore the relevant social groups, transform existing technologies into digital form. The impact of digitalization on society does not matter much, since digitalization is explained as a process arising from social practices. (2) Co-production approaches focus on shaping and reconciling technological and social evolution, avoiding both social and technological determinism. Thus, co-production is symmetrical with a simultaneous emphasis on both social values and needs of society and innovative opportunities for the implementation and adaptation of technological solutions in the context of resource, cultural, political, and economic realities. Accordingly, digitalization is considered a phenomenon in which social and technical needs and opportunities intersect and are mutually constructive. (3) From the point of view of posthumanistic and material-semiotic approaches, technology and society are divided into many different parts and heterogeneous practices, which merge into socio-technical communities. Digitalization, in the context of these approaches, can be described as a process in which a wide range of heterogeneous human and technological subjects form socio-digital communities and communication networks, materializing digital reality.

Cloud computing is having an unprecedented impact on the development of modern cities, equipped with the basic infrastructure to ensure a decent quality of life through the use of some smart solutions. City residents have access to various services that can be used via the Internet on their smartphones, laptops, personal computers, tablets. Improving the quality of life through the use of urban informatics and technologies, improving services, and meeting the needs of residents are a priority for local governments.

Cloud computing is needed in every urban infrastructure today, including transportation, energy, economic and social development, the environment, health and education [20]. Without cloud integration, it is almost impossible to visualize the infrastructural and social modernization of a city, aimed at improving public safety, efficient energy consumption, and developing a cohesive society. The main advantages of using cloud technologies in the development of modern cities include [21]: effective data management, support for the sustainability factor, growth in economic indicators of city development, cost reduction, and the provision of better services. 
Modern cities can take advantage of cloud solutions in infrastructure, platforms and applications (IaaS, PaaS, SaaS), services with cloud platforms and tools in the use of cloud technologies, as well as changes in applications and e-services as they migrate to the cloud [22]. The digital platform is the foundation that establishes, organizes, and manages the components and services of modern cities through the mechanism for managing hardware components and transmitted data [23].

In connection with the emergence and expansion of new digital trends in the development of territorial units, there is a need to structure the socio-economic effects from the introduction of innovative technologies based on cloud computing. For this purpose, an online conference was held, dedicated to identifying the impact of cloud technologies on the social life of society in the era of digitalization in a regional context. On the Zoom platform, representatives of the IT business, government authorities, and the educational sphere discussed the benefits of implementing cloud solutions in strategic projects for the development of the regional economy, social and human capital. The discussion was attended by representatives of government, business, science, and education of the Republics of Karelia, Komi, Adygea, Dagestan, Ingushetia, Kalmykia, Karachay-Cherkessia, Krasnodar Krai and Stavropol Krai (Russian Federation). The number of conference participants was 250 people.

The conference was held in September 2020 with a duration of 3 working days. Discussion topics were structured as follows:

Day 1-identifying the problems of socio-economic development of the Russian Federation regions in the context of global digital challenges;

Day 2-determining the technological capabilities of cloud solutions in the modernization of social infrastructure and the development of the digital potential of territorial units;

Day 3-identifying the strategic effects of cloud technologies on social life in the era of digitalization.

The practical part of the conference was aimed at developing projects for the implementation of cloud technologies in strategically important regions' aspects.

\section{$3 \quad$ Results and discussion}

The results of the experiment show that the implementation of cloud solutions at the regional development level has such key effects as social and human capital foundation, improvement the quality and standard of living in a region and social interaction, development of social constructivism, economic potential and competitiveness of social capital (Figure 2). According to the Figure 2 cloud technologies created by the process of digitalization influence on different aspects of social life in the region. All of them are implemented at different levels of impact. 


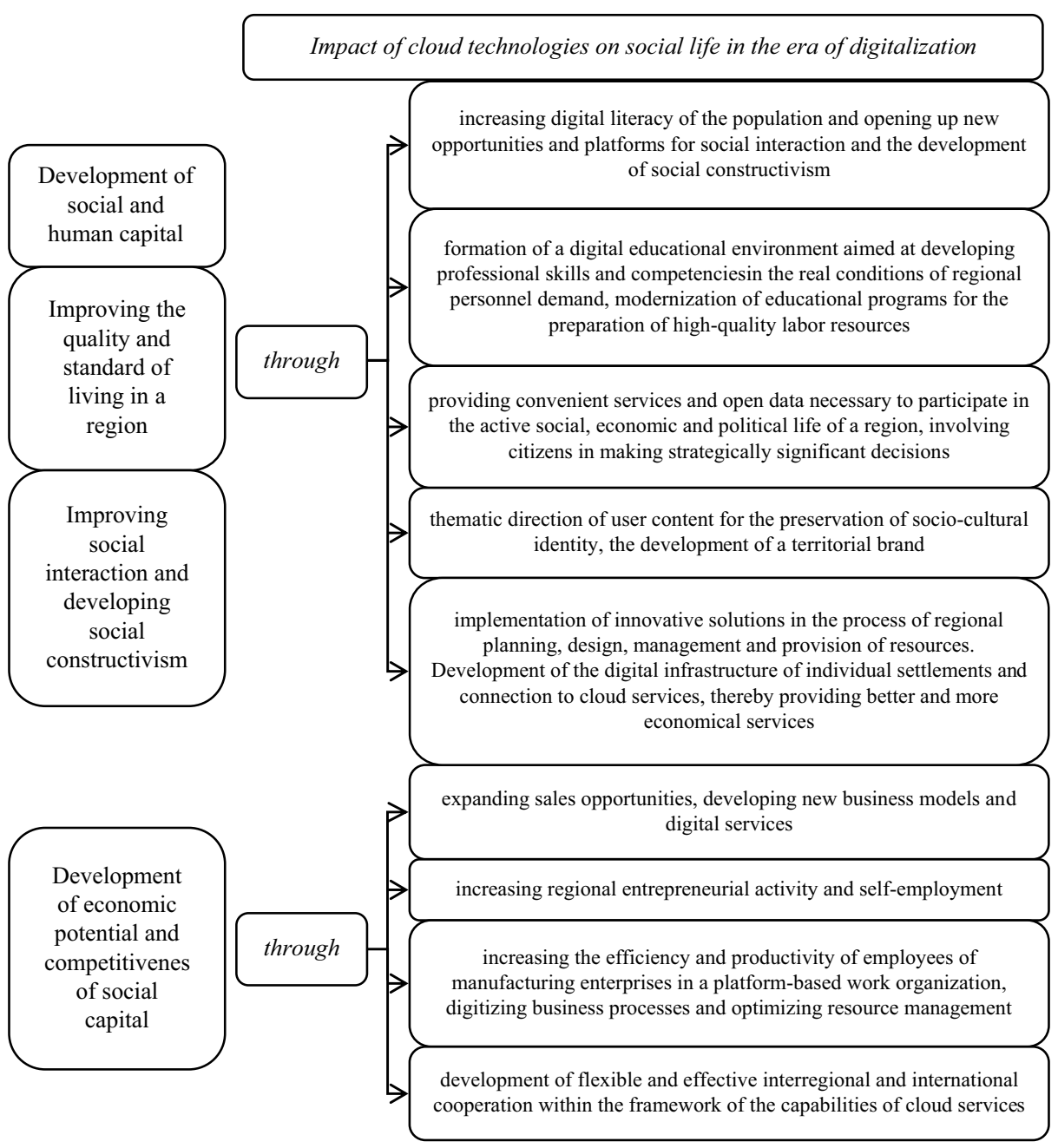

Fig. 2. Impact of cloud technologies on social life in the era of digitalization.

Developed by the authors

The Figure 2 represents the results of the discussion where the participants identified the functional effects of cloud technologies on social life in the era of digitalization. On the basis of them it was identified that the positive social effects of cloud technologies at the level of regional development were achieved by:

- increasing digital literacy of the population and opening up new opportunities and platforms for social interaction and constructivism;

- providing the population with convenient services and open data for participation in active social, economic, and political life;

- formation of a digital educational environment and modernization of educational programs for the preparation of high-quality labor resources; 
- development of digital infrastructure of individual settlements and connection to cloud services;

- creating thematic user content to preserve socio-cultural identity and popularize the region in the global information space.

Based on the results of the experiment it was revealed that the functionality of cloud technologies affects the improvement of standard of living and provides the increasing of labor resources efficiency and productivity by:

- expanding the marketing capabilities of business structures, providing them with new business models and digital services;

- optimization of resource management, digitization of business processes, and platform organization of labor.

As the advantages of the impact of cloud technologies on the social life (see Figure 2) he capabilities of cloud solutions allow for the formation of flexible and effective interregional and international cooperation in a region, having a positive impact on the regional economy and social capital development.

The academic and business literature has extensively debated the impact of cloud computing on business, government, and consumers. In comparison with the results represented on the Figure 2 the main advantages of cloud services in the context of business and government are savings the IT services costs from 10 to $30 \%$. Improved productivity is a positive benefit in medium or long term for businesses and governments. Serviceability is a positive benefit for consumers, especially in a corporate relationship environment where employees use cloud services for business purposes [9].

Information technology is a vital aspect of a business, helping to reduce costs, improve customer service, modernize manufacturing operations and corporate communication [24]. The European Social Observatory (OSE) has conducted research on the impact of digitalization on the content and quality of jobs. The results showed that new technologies are affecting workflows. Approximately $66 \%$ of surveyed employees confirmed that information and communication technologies allow them to focus on complex tasks since secondary, repetitive work functions can be performed by a computer automatically [25]. Research has also shown that digital technologies involved in business processes can improve productivity and work efficiency [26]. In addition, employees' job satisfaction rises, the work-life balance is blurred, which contributes to increased levels of autonomy. Since job satisfaction is closely related to employee turnover, it is an important criterion for the success of any company. Leveraging new technologies such as the Internet, virtual reality, automated manufacturing, and expert systems gives organizations the advantage of delivering high-quality products and better customer service [27].

Labor markets and work processes have changed dramatically with the advent of information and communication technologies [28]. Since innovative technologies create new jobs and processes, there is a change in working conditions, work tasks, physical, psychological and environmental requirements for personnel. In addition, significant changes are taking place in the conditions of employment and industrial relations between employers and employees [29]. Cloud computing technologies are contributing to a useful new work organization that includes greater autonomy in terms 
of the workplace, working hours, or performing various tasks [30]. On the other hand, increasing their use among employees makes it easier to monitor professional activities, providing a higher degree of centralization [31]. For example, one of the forms of employment that has appeared and is rapidly developing in the platform economy is the crowd work [32], which involves the transfer of business functions and tasks through Internet platforms to external parties who perform this work online in the digital cloud from different places around the world [33].

Create cloud-based applications using flexible cloud services is popular among companies looking to increase the business operations efficiency, productivity and flexibility. Cloud computing is an important factor in centralized storage of information and decentralized access to information, which gives employees the ability to communicate faster and more easily share service knowledge from different locations and in real time [34].

Cloud computing offers scalability in terms of resource use, low administration costs, flexible pricing model, and mobility for the software user. The cloud computing paradigm is especially popular in the environment of large business projects related to big data and business intelligence [35].

Cloud computing enables fast and secure management functions [36]. They provide access to business intelligence and hardware resources without upfront capital investment, which reduces time to market for many enterprises. The adoption of cloud computing promotes the innovative development of both individual business elements and sectors of the economy, removing IT barriers to innovation [16]. The most tangible benefits of cloud computing are cost savings, as they can reduce capital expenditures such as purchasing high-performance computers and buying company's own server for small and medium-sized businesses. In addition, the service improves the internal organizational processes of a company, helps to accelerate decision-making, expand markets, and improve communication with customers [37].

In addition to the positive effects, the negative effects of cloud services are considered and discussed in academia. There is a risk of losing control over the data or its confidentiality and the risk of the data being unavailable when needed. These risks affect all types of users, from businesses to governments and consumers. In particular, there is a risk for consumers to sacrifice privacy, as many advertising or free services, such as webmail services, rely on the analysis of user data [9].

\section{Conclusion}

Based on the study results, key strategic effects from the implementation of cloud solutions in the Russian Federation regions in the context of the innovative capabilities of the platform economy were identified. The results of the experiment based on the study of the influence of the implementation of cloud solutions on the regional development level show such effects as social and human capital foundation, improvement the quality and standard of living in a region and social interaction, development of social constructivism, economic potential and competitiveness of social capital. The analysis of the received results indicates the positive social effects of cloud technologies at the level of a territorial unit are achieved by increasing digital literacy of the population 
and opening up new opportunities and platforms for social interaction and constructivism; providing the population with convenient services and open data for participation in active social, economic and political life. Based on the experiment it's determined that cloud technologies help to form a digital educational environment, modernize educational programs for the preparation of high-quality labor resources, develop digital infrastructure of individual settlements, create user content to preserve socio-cultural identity, and popularize a region in the global information space. The results of the experiment also show the opportunity to increase the population quality of living and ensure the growth of the efficiency and productivity indicators of labor resources with the help of cloud technologies. The practical significance of the study is explained by the opportunity to analyze the level of specific cloud technologies on the different aspects of social life based on the comparative experiment of the experience of different countries. The prospects for the further research can be based on the study of the capabilities of cloud technologies in the formation of flexible and effective interregional and international cooperation in a region, having a positive impact on regional economy and social capital development.

\subsection{Study limitation}

The assessment of social effects from the implementation of cloud solutions is based on the opinions of stakeholders in the infrastructural development of regions and demonstrates only a conceptual outline of the benefits of technological modernization of socio-economic life. The identified social effects can become an incentive for the implementation of cloud solutions in strategic projects for the development of the regional economy of the Russian Federation, social and human capital, as well as open new vectors of social constructivism.

\section{$5 \quad$ Acknowledgment}

Elena Panfilova was supported in part within the framework of the state project No. 1 Analyzing Readiness of the Russian Society for Digitalization under the Terms of a Donation Agreement No. 1154, dated March 1, 2019.

\section{References}

[1] Komarova, A., Tsvetkova, L., Kozlovskaya, S., Pronkin, N. (2019). Organisational educational systems and intelligence business systems in entrepreneurship education. Journal of Entrepreneurship Education, 22(5): 1-15.

[2] Messner, D., Nakicenovic, N., Zimm, C., Clarke, G., Rockström, J., Aguiar, A.P., Boza-Kiss, B., Campagnolo, L., Chabay, I., Collste, D., Comolli, L., Gómez-Echeverri, L., Goujon, A., Grubler, A., Jung, R., Kamei, M., Kamiya, G., Kriegler, E., Kuhn, M., Leininger, J., Martin-Shields, C., Mayor-Rodriguez, B., Miller, J., Miola, A., Riahi, K., Schewenius, M., Schmidt, J., Skierka, K., Selomane, O., Svedin, U., Yillia, P. (2019). The Digital Revolution and Sustainable Development: Opportunities and Challenges, Report prepared by The World in 2050 initiative. International Institute for Applied Systems Analysis (IIASA). 
[3] Musik, C., Bogner, A. (2019). Digitalization and society: A sociology of technology perspective on current trends in data, digital security and the internet. Springer VS. https://doi. org/10.1007/s11614-019-00344-5

[4] Varghese, B., Prades, J., Reao, C., Silla, F. (2015). Acceleration-as-a-service: Exploiting virtualised GPUs for a financial application. In 11th IEEE International Conference on e-Science. IEEE, pp. 47-56. https://doi.org/10.1109/eScience.2015.15

[5] Gubbi, J., Buyya, R., Marusic, S., Palaniswami, M. (2013). Internet of things (IoT): A vision, architectural elements, and future directions. Future Generation Computer Systems, 29(7): 1645-1660. https://doi.org/10.1016/j.future.2013.01.010

[6] Katzenbach, C., Bächle, T.C. (2019). Defining concepts of the digital society. Internet Policy Review, 8(4): 1-6. https://doi.org/10.14763/2019.4.1430

[7] Kenney, M., Zysman, J. (2016). The rise of the platform economy. Issues Science and Technology, 32: 61-69.

[8] Couldry, N., Mejias, U.A. (2019). Data colonialism: Rethinking big data's relation to the contemporary subject. Television \& New Media, 20(4): 336-349. https://doi. org/10.1177/1527476418796632

[9] Leimbach, T., Hallina, D., Bachlechner, D., Weber, A., Jaglo, M., Hennen, L., Nielsen, R.Ø., Hunt, G., Strauß, S., Nentwich, M., Lynn, T.G. (2014). Potential and Impacts of Cloud Computing Services and Social Network Websites. Fraunhofer ISI.

[10] Degele, N. (2002). Einführung in die Techniksoziologie. Wilhelm Fink.

[11] El-Seoud, S.A., El-Sofany, H.F., Abdelfattah, M.A.F., Mohamed, R. (2017). Big data and cloud computing: Trends and challenges. International Journal of Interactive Mobile Technologies, 11(2): 34-52. https://doi.org/10.3991/ijim.v11i2.6561

[12] Sawas, M., Watfa, M. (2015). The impact of cloud computing on information systems agility. Australasian Journal of Information Systems, 19: 97-112. https://doi.org/10.3127/ajis. v19i0.930

[13] Varghese, B., Buyya, R. (2018). Next generation cloud computing: New trends and research directions. Future Generation Computer Systems, 79: 849-861. https://doi.org/10.1016/j. future.2017.09.020

[14] Arnold, B., Baset, S.A., Dettori, P., Kalantar, M., Mohomed, I.I., Nadgowda, S.J., Sabath, M., Seelam, S.R., Steinder, M., Spreitzer, M., Youssef, A.S. (2016). Building the IBM containers cloud service. IBM Journal of Research and Development, 60(2-3): 1-12. https://doi. org/10.1147/JRD.2016.2516943

[15] Trivedi, R.K., Sharma, R. (2014). Case study on environmental impact of cloud computing. IOSR Journal of Computer Engineering, 16(2): 81-86. https://doi.org/10.9790/066116268186

[16] Avram, M.G. (2014). Advantages and challenges of adopting cloud computing from an enterprise perspective. Procedia Technology, 12: 529-534. https://doi.org/10.1016/j. protcy.2013.12.525

[17] Buyya, R., Yeo, C.S., Venugopal, S., Broberg, J., Brandic, I. (2009). Cloud computing and emerging IT platforms: Vision, hype, and reality for delivering computing as the 5th utility. Future Generation Computer Systems, 25(6): 599-616. https://doi. org/10.1007/978-3-642-10665-1 4

[18] Kim, W. (2009). Cloud computing: Today and tomorrow. Journal of Object Technology, 8(1): 65-72. https://doi.org/10.5381/jot.2009.8.1.c4

[19] Qasem, M.N., Abu-Srhan, A., Natoureah, H., Alzaghoul, E. (2020). Fog computing framework for smart city design. International Association of Online Engineering, 14: 109-125. https://doi.org/10.3991/ijim.v14i01.9762

[20] Movchun, V., Lushkov, R., Pronkin, N. (2020). Prediction of individual learning style in e-learning systems: opportunities and limitations in dental education. Education and Information Technologies, 1: 1-15. 
[21] Smartcity. (2018). Smart Cities Need To Be On The Cloud To Speed Up Sustainable Development. https://www.smartcity.press/cloud-computing-benefits/

[22] Agarwal, N., Agarwal, G. (2017). Role of cloud computing in development of smart city. In National Conference on Road Map for Smart Cities of Rajasthan, pp. 2349-2784.

[23] Qasem, M.N., Al Mobaideen, W. (2019). Heterogeneity in IoT-based smart cities designs. International Journal of Interactive Mobile Technologies, 13: 210-225. https://doi. org/10.3991/ijim.v13i12.9763

[24] Ratna, R., Kaur, T. (2016). The impact of information technology on job related factors like health and safety, job satisfaction, performance, productivity and work life balance. Journal of Business \& Financial Affairs, 5(1): 2167-2234. https://doi.org/10.4172/2167-0234.1000171

[25] Peña-Casas, R., Ghailani, D., Coster, S. (2018). The impact of digitalisation on job quality in European public services. The case of homecare and employment service workers. European Social Observatory (OSE) and European Public Service Union (EPSU).

[26] Vuori, V., Helander, N., Okkonen, J. (2019). Digitalization in knowledge work: The dream of enhanced performance. Cognition, Technology \& Work, 21: 237-252. https://doi. org $/ 10.1007 / \mathrm{s} 10111-018-0501-3$

[27] Cijan, A., Jenič, L., Lamovšek, A., Stemberger, J. (2019). How digitalization changes the workplace. Dynamic Relationships Management Journal, 8(1): 3-12. https://doi. org/10.17708/DRMJ.2019.v08n01a01

[28] Chesley, N. (2010). Technology use and employee assessments of work effectiveness, workload, and pace of life. Information, Communication \& Society, 13(4): 485-514. https://doi. org $/ 10.1080 / 13691180903473806$

[29] Enrique, F.M. (2018). Automation, digitalisation and plat-forms: Implications for work and employment. Eurofound. https://www.eurofound.europa.eu/publications/report/2018/ automation-digitisation-and-platforms-implications-for-work-and-employment

[30] Gibbs, M. (2017). How is new technology changing job design? IZA World of Labor, 1: 344. https://doi.org/10.15185/izawol.344

[31] Gerten, E., Beckmann, M., Bellmann, L. (2019). Controlling working crowds: The impact of digitalization on worker autonomy and monitoring across hierarchical levels. Jahrbücher für Nationalökonomie und Statistik, 239: 441-481. https://doi.org/10.1515/jbnst-2017-0154

[32] Gerber, C., Krzywdzinski, M. (2017). Schöne neue Arbeitswelt? Durch Crowdworking werden Aufgaben global verteilt. WZB-Mitteilungen, 155: 6-9.

[33] Krzywdzinski, K., Evers, M., Gerber, C. (2018). The Social Consequences of the Digital Revolution. In P. Basso, G. Chiaretti (eds.), Le grandi questioni sociali del nostro tempo. Edizioni Ca'Foscari, pp. 101-120. https://doi.org/10.30687/978-88-6969-273-4/008

[34] European Economic and Social Committee (2017). Impact of digitalisation and the on-demand economy on labour markets and the consequences for employment and industrial relations. https://www.eesc.europa.eu/en/our-work/publications-other-work/publications/ impact-digitalization-and-demand-economy-labour-markets-and-consequences-employment-and-industrial-relations

[35] Shim, K., Cha, S.K., Chen, L., Han, W.S., Srivastava, D., Tanaka, K., Yu, H., Zhou, X. (2012). Data management challenges and opportunities in cloud computing. In S. Lee, Z. Peng, X. Zhou, Y.S. Moon, R. Unland, J. Yoo (eds.), 17th International Conference on Database Systems for Advanced Applications (DASFAA'2012). Springer, pp. 323-323. https:// doi.org/10.1007/978-3-642-29035-0 30

[36] Malla, M., Pasumarti, S.S., Dhal, S.K., Nath, S.C. (2020). A study on impact of cloud based computing on performance of human resources in selected IT industry in Odisha. International Journal of Scientific \& Technology Research, 9(1): 2716-2723.

[37] Widyastuti, D., Irwansyah, I. (2017). Benefits and challenges of cloud computing technology adoption in Small and Medium Enterprises (SMEs). Bandung Creative Movement Journal, 41(1): 241-246. 


\section{Authors}

Elena Panfilova is a PhD of Economic Sciences, Associate Professor of the Department of Management Organization in Engineering, State University of Management, Moscow, Russian Federation.

Anna Lukyanova is a Doctor of Economic Sciences, Professor of the Department of Business Administration, Faculty "Higher School of Management", Financial University under the Government of the Russian Federation, Moscow, Russian Federation.

Nikolay Pronkin is a PhD of Economic Sciences, Associate Professor of the Department of Medical Computer Science and Statistics, Sechenov First Moscow State Medical University (Sechenov University), Moscow, Russian Federation.

Elena Zatsarinnaya is a $\mathrm{PhD}$ of Economic Sciences, Associate Professor of the Base Department Financial Control, Analysis and Audit Main Control Department of the City of Moscow, Plekhanov Russian University of Economics, Moscow, Russian Federation.

Article submitted 2021-03-30. Resubmitted 2021-08-27. Final acceptance 2021-08-28. Final version published as submitted by the authors. 